\title{
Ornithopod and Sauropod Dinosaur Remains from the Maastrichtian Al-Khod Conglomerate, Sultanate of Oman
}

\author{
Ann S. Schulp*, Patrick M.O'Connor**, David B. Weishampel*k*, Abdul Razak Al \\ Sayigh, Abdulrahman Al-Harthy"****, John W.M. Jagt and Axel F. Hartman*****.
}

Natuurhistorisch Museum Maastricht, De Bosquetplein 6/7, NL6211KJ Maastricht, The Netherlands, ${ }^{\star}$ Email: anne.schulp@maastricht.nl; ${ }^{\star *}$ Ohio University, Department of Biomedical Sciences, 228 Irvine Hall, Athens, $\mathrm{OH}$

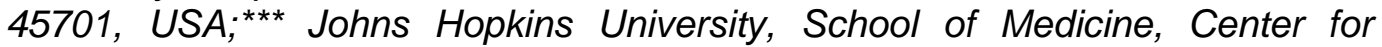
Functional Anatomy \& Evolution, 1830 E Monument Street, Baltimore, MD

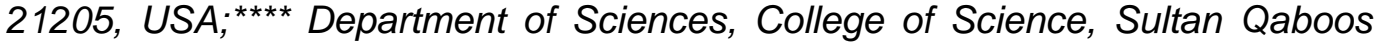
University, P.O.Box 36, Al-Khod 123, Muscat, Sultanate of Oman; ${ }^{\star \star * \star * B r u n e i}$ Shell Petroleum, EPE/21 BSP Brunei, P.O. Box 245, NL 2501CE Den Haag, The Netherlands.

\section{أورنيثوبود وثوروبود بقليا اليناصورل من المستربختن الخوض كونجلومتيرات (الحصى المتلحمة)}

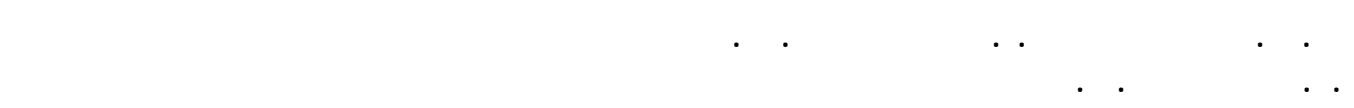

خلاصة: أدت الدرلسلت الميدانية إلى لكتشف عظلم بيناصور مقرض في رولمب مفتتلت صخرية يزيد عمرها على 65

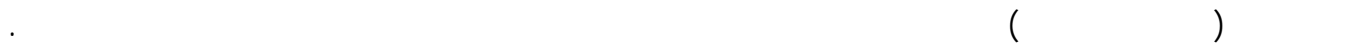

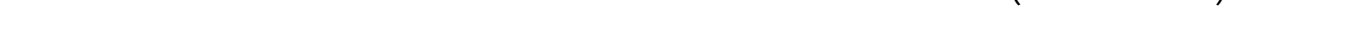

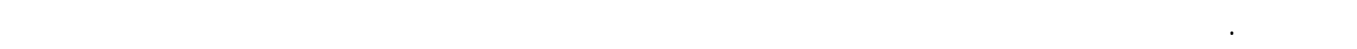

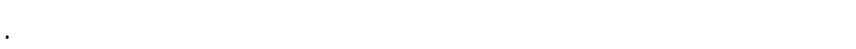

ABSTRACT: Fieldwork in the Upper Cretaceous (Maastrichtian) Al-Khod Conglomerates in the Sultanate of Oman led to the discovery of a large bone fragment tentatively identified as a partial distal left humerus of a sauropod and an ornithopod dorsal vertebra. The very fragmentary state of preservation of the dorsal vertebra makes specific attribution difficult, but it shows remarkable similarities to the rhabdodontid dinosaurs Rhabdodon and Zalmoxes.

KEYWORDS: Sultanate of Oman; Late Cretaceous; Maastrichtian; Dinosauria; Ornithopoda; Sauropoda. 


\section{Introduction}

D inosaur fossils in the Sultanate of Oman were recognized for the first time by Nolan et al. (1990) while logging the type section of the Al-Khod Conglomerate Formation. A short reconnaisance in 1997 by two of us (ASS and AFH) confirmed the potential of the Al-Khod Conglomerate outcrops for further vertebrate palaeontological fieldwork. During this reconnaisance, one of us (AFH) discovered a theropod caudal vertebra (Schulp et al., 2000). Subsequent fieldwork in 1998 (e.g. Buscalioni et al., 2004) yielded additional material, of which an ornithopod dorsal vertebra and a fragmentary sauropod humerus are described in the present contribution.

\section{Material}

Institutional abbreviations - All fossil material recovered from Al-Khod is permanently deposited in the collections of the Sultan Qaboos University, Sultanate of Oman. The specimens described here are numbered SQU-2-65 and SQU-2-76, respectively, where '2' refers to the Al-Khod-locality.

Locality - Both elements described here were recovered from the type locality of the Al-Khod Conglomerate Formation (Nolan et al. 1990; Schulp et al., 2000; Buscalioni et al., 2004), located approximately 30 km west of Muscat, Sultanate of Oman.

Age - The Al-Khod Conglomerate Formation has previously been assigned a Maastrichtian age (see Nolan et al., 1990; Schulp et al., 2000). The stratigraphy and sedimentology of these deltaic deposits are described in detail in these contributions, and is not repeated here. Recent analysis (by AA-S) of microfossils from the base of the Jafnayn Formation (which conformably overlies the Al-Khod Conglomerate) confirms the Maastrichtian age of the Al-Khod Conglomerate.

\section{SYSTEMATIC PALAEONTOLOGY}

DINOSAURIA Owen, 1842

SAURISCHIA Seeley, 1888

SAUROPODA Marsh, 1878

(Figure 1A-C)
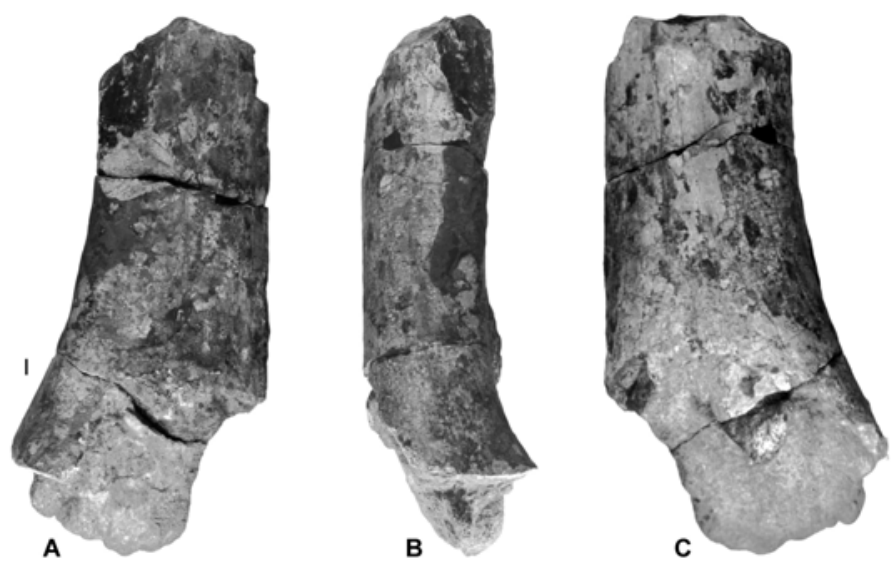

Figure 1. SQU-2-65 - Sauropod left distal humerus from the Maastrichtian Al-Khod Conglomerate Formation, Sultanate of Oman, in cranial (A), medial (B) and caudal (C) views. Scale bar equals $10 \mathrm{~mm}$. 


\section{ORNITHOPOD AND SAUROPOD DINOSAUR}

Specimen - SQU-2-65 is a partial distal left humerus, collected by AFH as three isolated fragments in float from the lowermost part of the section.

Description - Although the specimen was collected as three separate fragments, morphology of the fracture surfaces allows a confident assembly of the individual pieces into a single element (Figure 1). We tentatively interpret the specimen to represent the distal half of a left humeral diaphysis of an indeterminate sauropod, spanning from just below mid-shaft to the expanded region just proximal to the ulnar and radial condyles. The medial edge of the element is better preserved than the lateral, the former extending approximately $6 \mathrm{~cm}$ further distally than the latter (Figure 1A). The element exhibits a maximum length (proximodistal) of $34 \mathrm{~cm}$, with a $31.5 \mathrm{~cm}$ diaphyseal circumference at the proximal end. The proximal surface is elliptical in cross-section, with the long axis oriented transversally $(11.5 \mathrm{~cm}$ mediolaterally by $8.5 \mathrm{~cm}$ craniocaudally). The distal end of the diaphysis is deflected cranially (Figure 1B). Although incomplete distally, it is apparent that the mediolateral flaring characteristic of sauropod humeri is asymmetric, being more pronounced along the medial edge. A slight ridge is present on the craniomedial edge of the element (Figure 1A) and forms the medial border of a shallow fossa on the cranial surface. The caudal aspect is poorly preserved (Figure 1C), with original bone surface only remaining on the proximal two-third of the element. Although the proximal portion of the olecranon fossa is preserved (Figure 1C), incomplete preservation of the caudodistal end renders the determination of either (1) the size and position of supracondylar ridges (and thus the relative development the olecranon fossa) or (2) the shape, position, and relative sizes of the radial and ulnar condyles impossible.

ORNITHISCHIA Seeley, 1888

ORNITHOPODA Marsh, 1881

(Figure 2A-D)
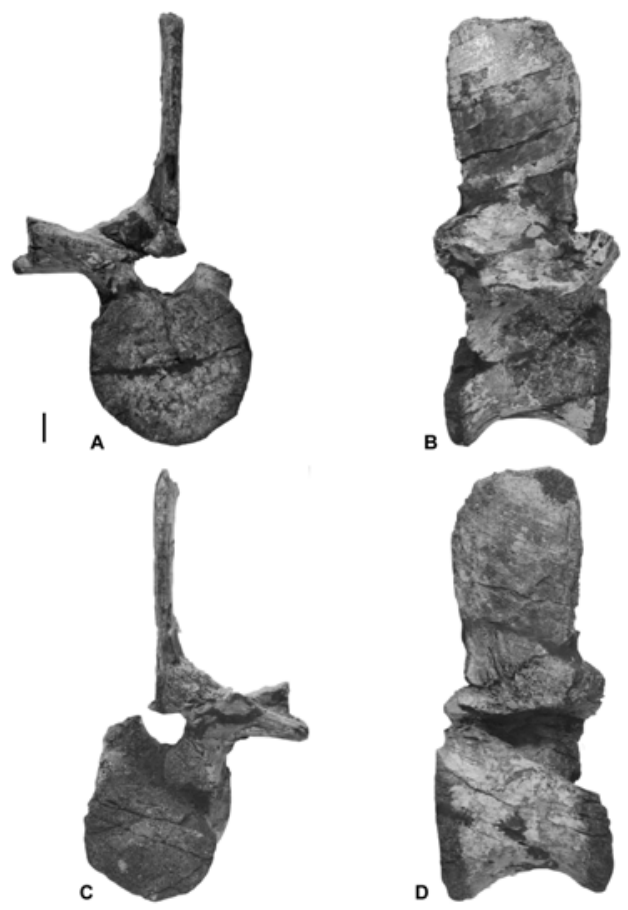

Figure 2. SQU-2-76 - Ornithopod dorsal vertebra from the Maastrichtian Al-Khod Conglomerate Formation, Sultanate of Oman, in posterior (A), left lateral (B), anterior (C) and right lateral (D) views. Scale bar equals 10 $\mathrm{mm}$. 


\section{ANNE S. SCHULP ET AL.}

Specimen - SQU-2-76 is a vertebral centrum with partially preserved neural arch.

Description - This mid-dorsal vertebra of an as yet undetermined rhabdodontid dinosaur is undeformed and nearly complete, lacking only the left transverse process, the adjoining quarter of the caudal aspect of the centrum, and the pre- and postzygapophyses. The centrum is broadly spindle shaped, slightly longer than high the axial length is $60 \mathrm{~mm}$ while the centrum is $58 \mathrm{~mm}$ wide and $53 \mathrm{~mm}$ tall. The cranial and caudal surfaces are parallel to each other in lateral view and both are relatively circular (with a small dorsal indentation for the neural canal) and slightly amphiplatyan. In lateral view, the centrum has a prominent ventral concavity between the cranial and caudal margins. Here it forms a gently rounded surface that is continued as the compressed lateral walls of the centrum. Only a faint expression of the neurocentral suture is visible on the right side of the specimen, probably indicating that the individual was close to reaching skeletal maturity. The thick pedicle arches laterally to form the base of the transverse process. The neural canal, surrounded by the pedicle and stout lamina that forms the base of the neural spine, is ovate and of moderate size (transverse diameter of the neural canal is $40 \%$ transverse diameter of the centrum). The neural arch and spine extend nearly the entire length of the centrum. The neural spine is moderately thick, tall, and rectangular. Its dorsal edge is only slightly expanded. The parapophysis, for the capitulum of the associated rib, is positioned beneath the intersection of the pedicle and transverse process.

\section{Discussion}

Asymmetric flaring of the sauropod distal humerus in SQU-2-65 is reminiscent of the condition observed in several lithostrotians such as Rapetosaurus (Curry Rogers and Forster 2001, Figure 3E), Paralititan (Smith et al., 2001, Figure 2A), and to a lesser degree Malawisaurus (Gomani, 2005, Figure 20). Moreover, it is unlike the symmetrical flaring observed in saltasaurids (i.e., derived lithostrotians; see Upchurch, 1998, Figure 12), not to mention many other (non-lithostrotian) sauropod taxa (e.g., diplodocoids). Although the absence of other diagnostic features in SQU-2-65 does not allow for a more specific assignment, the potential lithostrotian affinities outlined for it are generally consistent with the known distribution of specific sauropod subclades in Maastrichtian-age strata. The latest Cretaceous sauropod record of Afro-Arabia is extremely limited (Weishampel et al., 2004) and includes only three Maastrichtian occurrences, an associated basal titanosauriform hind limb from Morocco (Pereda-Suberbiola et al., 2004), a possible 'brachiosaurid' femur from Egypt (Rauhut and Werner, 1997), and a dorsal vertebra referred to Titanosauria from Jordan (Wilson et al., 2006). From the Arabian Peninsula, the only sauropod occurrences thus far reported (e.g., fragmentary vertebrae; tracks) are from Jurassic strata exposed in northern Yemen (Jacobs et al., 1999; Schulp et al., 2008).

Although SQU-2-76 lacks apomorphies known for Rhabdodontidae or the three members of this group (see Weishampel et al., 2003), the vertebra from Oman is closely similar to the dorsals of those ornithopods of about the size and phylogenetic position as species of Rhabdodon and Zalmoxes. However, they differ from those of Tenontosaurus, the latter being dorsoventrally ovate in cranial/caudal views (Ostrom, 1970) and of Thescelosaurus and Dryosaurus, which have highly elevated transverse processes (Gilmore, 1915; Galton 1974, 1981). The latest Cretaceous ornithopod record of Afro-Arabia is even more limited than the sauropod record (Weishampel et al., 2004; Lamanna et al., 2004; see also Martill et al., 1996), which underscores the palaeobiogeographical significance of the Al-Khod Conglomerate.

\section{Conclusion}

The Maastrichtian Al-Khod dinosaurian fauna comprises at least three taxa: a medium-sized theropod (Schulp et al., 2000), a small ornithopod, and a medium-sized sauropod. Based on the presence of the three dinosaurian taxa, along with two previously reported crocodyliforms (Buscalioni et al., 2004) and other as yet undescribed forms (e.g., turtles), the Al-Khod Conglomerate Formation has yielded the taxonomically most diverse terrestrial vertebrate fauna from the latest Cretaceous of the Middle East. Moreover, it represents one of 


\section{ORNITHOPOD AND SAUROPOD DINOSAUR}

the very few temporally constrained Late Cretaceous vertebrate-bearing locales in all of Afro-Arabia. The generally poor state of preservation however, is most unfortunate, as it in most cases precludes specific taxonomic assignment.

\section{Acknowledgements}

The research was conducted by the Sultan Qaboos University, Al-Khod, Sultanate of Oman, the Natuurhistorisch Museum Maastricht and the Vrije Universiteit Amsterdam, The Netherlands, supported in various ways by the Petroleum Development of Oman, Shell International Exploration and Production, and the Molengraaff Foundation. Three anonymous reviewers provided helpful feedback.

\section{References}

BUSCALIONI, A.D., SCHUlP, A.S., JAGT, J.W.M., HANNA, S.S. and HARTMAN, A.F. 2004. Late Cretaceous neosuchian crocodiles from the Sultanate of Oman. Cretaceous Research, 25: 267-275.

CURRY ROGERS, K. and FORSTER, C.A. 2001. The last of the dinosaur titans: a new sauropod from Madagascar. Nature 412: 530-534.

GALTON, P.M. 1974. Notes on Thescelosaurus, a conservative ornithopod dinosaur from the Upper Cretaceous of North America, with comments on ornithopod classification. Journal of Paleontology 48: 1048-1067.

GALTON, P.M. 1981. Dryosaurus, a hypsilophodontid dinosaur from the Upper Jurassic of North America and Africa: Postcranial skeleton. Paläontologische Zeitschrift, 55: 271-312.

GILMORE, C.W. 1915. Osteology of Thescelosaurus, an ornithopodous dinosaur from the Lance Formation of Wyoming. Proceedings of the United States National Museum, 49: 591-622.

GOMANI, E.M. 2005. Sauropod dinosaurs from the Early Cretaceous of Malawi, Africa. Palaeontologia Electronica, 8:27A: 37 pp.

JACOBS, L.L., MURRY, P.A., DOWNS, W.R. and EL-NAKHAL, H.A. 1999. A dinosaur from the Republic of Yemen. In Fossil vertebrates of Arabia. eds P.J. Whybrow and A. Hill. Yale University Press, New Haven, CT. Pp. 454-459.

LAMANNA, M.C., SMITH, J.B., ATTIA, Y.S. and DODSON, P. 2004. From dinosaurs to dyrosaurids (Crocodyliformes): removal of the post-Cenomanian (Late Cretaceous) record of Ornithischia from Africa. Journal of Vertebrate Paleontology, 24: 764-768.

MARSH, O.C. 1878. Principal characters of American Jurassic Dinosaurs. Part I. American Journal of Science (3) 16: 411-416.

MARSH, O.C. 1881. Principal Characters of American Jurassic Dinosaurs, Part V. American Journal of Science, (3) 21: 417-423.

MARTILL, D.M., FREY, E. and SADAQAH, R.M. 1996. The first dinosaur from the Hashemite Kingdom of Jordan. Neues Jahrbuch für Geologie und Paläontologie, Monatshefte, 1996: 147-154.

NOLAN, S.C., SKELTON, P.W., CLISSOLD, B.P. and SMEWING, J.D. 1990. Maastrichtian to early Tertiary stratigraphy and palaeogeography of the central and northern Oman Mountains. In The geology and tectonics of the Oman region. eds A.H.F. Robertson, M.P. Searle and A.C. Ries. Geological Society London, Special Publication, 49: 495-519.

OSTROM, J.H. 1970. Stratigraphy and paleontology of the Cloverly Formation (Lower Cretaceous) of the Bighorn Basin area, Wyoming and Montana. Peabody Museum of Natural History Bulletin, 35: 1-234.

OWEN, R. 1842. Report on British fossil reptiles, part II. Report of the British Association for the Advancement of Science, 11: 60-204.

PEREDA-SUBERBIOLA, X., BARDET, N., IAROCHÈNE, M., BOUYA, B. and AMAGHZAZ, M. 2004. The first record of a sauropod dinosaur from the Late Cretaceous phosphates of Morocco. Journal of African Earth Sciences, 40: 81-88. 


\section{ANNE S. SCHULP ET AL.}

RAUHUT, O.W.M. and WERNER, C. 1997. First record of a Maastrichtian sauropod dinosaur from Egypt. Palaeontologica Africana, 34: 63-67.

SCHULP, A.S., HANNA, S.S., HARTMAN, A.F. and JAGT, J.W.M. 2000. A Late Cretaceous theropod caudal vertebra from the Sultanate of Oman. Cretaceous Research, 21: 851-856.

SCHULP, A.S., AL-WOSABI, M. and STEVENS, N.J. 2008. First Dinosaur Tracks from the Arabian Peninsula. PLOS ONE 3(5): e2243. doi:10.1371/journal.pone.0002243

SEELEY, H.G. 1888. The classification of the Dinosauria. Report of the British Association for the Advancement of Science 1887: 698-699.

SMITH, J.B., LAMANNA, M.C., LACOVARA, K.J., DODSON, P., SMITH, J.R., POOLE, J.C., GIEGENGACK, R. and ATTIA, Y. 2001. A giant sauropod dinosaur from an Upper Cretaceous mangrove deposit in Egypt. Science, 292: 1704-1706.

UPCHURCH, P. 1998. The phylogenetic relationships of sauropod dinosaurs. Zoological Journal of the Linnean Society, 124: 43-103.

WEISHAMPEL, D.B., BARRETT, P.M., CORIA, R.A., LELOEUFF, J., XING, X., XIJIN, Z., SAHNI, A., GOMANI, E.M.P. and NOTO, C.R. 2004. Dinosaur distribution. In The Dinosauria. eds D.B. Weishampel, P. Dodson and H. Osmólska. University of California Press, Berkeley/Los Angeles. Pp. 517606.

WEISHAMPEL, D.B., JIANU, C.M., CSIKI, Z. and NORMAN, D.B. 2003. Osteology and phylogeny of Zalmoxes (n.g.), an unusual euornithopod dinosaur from the latest Cretaceous of Romania. Journal of Systematic Palaeontology, 1: 65-123.

WILSON, J., MUSTAFA, H. and ZALMOUT, I. 2006. Latest Cretaceous reptiles from the Hashemite Kingdom of Jordan. Journal of Vertebrate Paleontology, Supplement to 26(3): 140A.

Received 29 December 2007

Accepted 31 January 2009 